5 Tang J, Wang B, Narușe R, et al. Does the propofol "sandwich" technique reduce PONV after inhalation anaesthesia. Anesth Analg 1997; 84: S554.

6 Gong $D H$, Weiskopf $R B$, Neumann MA, et al. In rats breathing from a nonrebreathing system, substitution of desflurane for isoflurane toward the end of anesthesia incompletely restores the time of recovery toward that of desflurane. Anesth Analg 1998; 86: 198-201.

7 Vellet AD, Lee D. Anecdote or science? Can Med Assoc J 1998; 158: 63-4.

\section{Fibreoptic laryngoscope blade}

To the Editor:

We would like to report the failure of a Heine \#4 fibreoptic laryngoscope blade (Heine Instruments (Canada), Ltd., Kitchener, Ontario) during a recent intubation.

A 42-yr-old, $92 \mathrm{~kg}$, ASA 2, lady presented for nasal and sinus surgery. No evidence of airway abnormality was detected pre-operatively. Anaesthesia was induced using protocol and a defasciculating dose of rocuronium before $120 \mathrm{mg}$ succinylcholine were given. An $8 \mathrm{~mm}$ Rae Mallinckrodt endotracheal tube was easily placed into the trachea using a Heine \#4 fibreoptic laryngoscope blade.

Upon withdrawing the laryngoscope from the mouth, the blade was closed against the handle. Immediately, a metallic sound was heard as a piece of the laryngoscope ricocheted off the anaesthetic machine and a quick search resulted in the discovery of a spring. The laryngoscope was examined thoroughly. The hookon base of the laryngoscope blade lacked the ball bearing portion of the hook-on locking apparatus (see Figure 2). The metal ball could not be found. Repeat visualisation of the patient's upper airway failed to locate the missing ball bearing. Similarly, radiographs of the patient's upper airway and chest were unsuccessful in locating the metal sphere. Eventually, the missing ball bearing was discovered in one of the partially open drawers of the anaesthetic machine.

The durability and structural integrity of laryngoscope blades are seldom a problem. Laryngoscope bulb and battery failure is common but laryngoscope blade structural failure is infrequent. ${ }^{3}$ It may exist in any facility where older Heine fibreoptic blades are in use.

Donald T. Jolly MD FRCP

Glenn Hawthorn RRT

Tony Wan BMET

Capital Health Authority

Department of Anaesthesia

University of Alberta Hospitals

Edmonton, Alberta, T6G 2B7

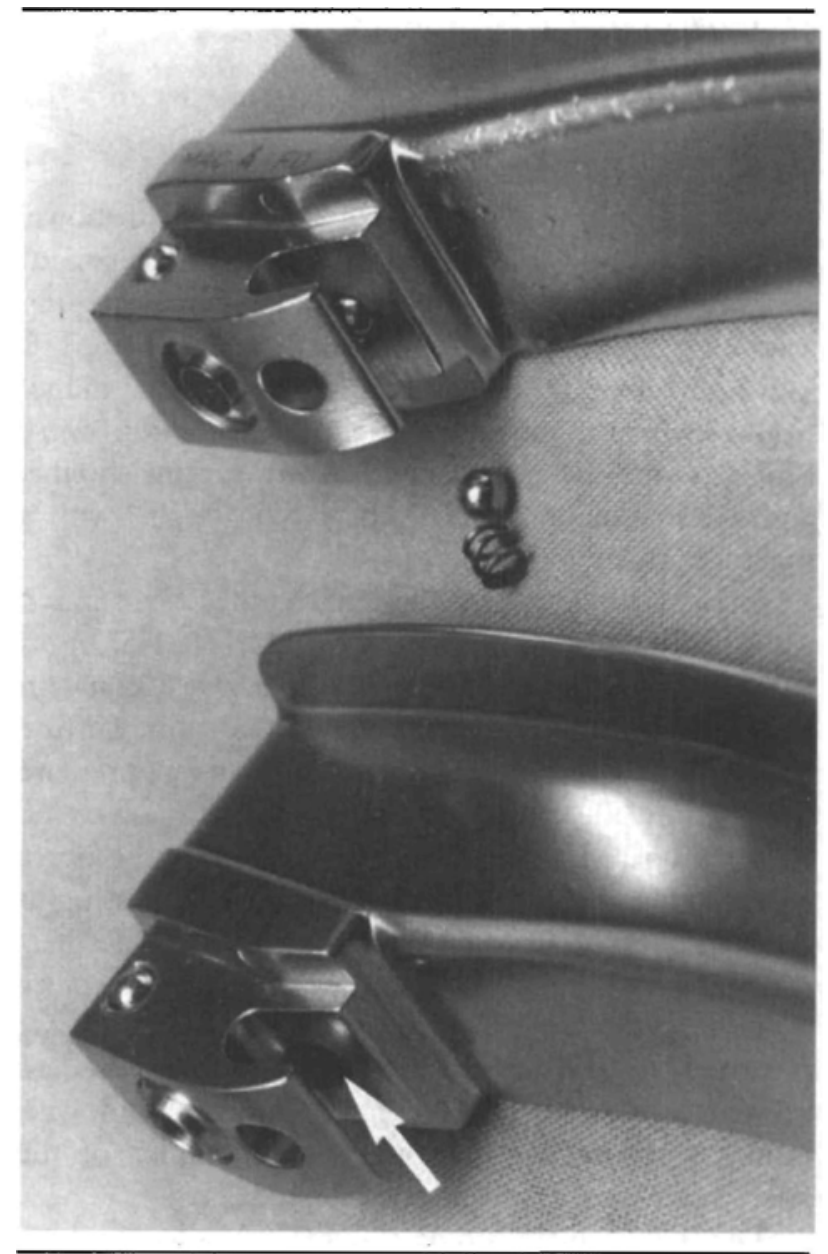

FIGURE 2 MAC \#4 Fibreoptic Heine laryngoscope blade

Top: Intact blade; Bottom: Blade missing the released ball bearing and spring (arrow)

(Photo courtesy. E. Poelzer)

\section{REPERENCE}

1 Gibson S, Kelly K. Pediatric laryngoscope blade failure (Letter). Anaesth Intensive Care 1996; 24: 724-5.

\section{Erratum}

Stein RD, Backman SB, Collier B, Polosa C. Bradycardia produced by pyridostigmine and physostigmine. Can J Anaesth 1997; 44: 1286-92.

On page 1287, first column, 9 th line from the bottom of the first paragraph, the word "unless" is incorrect and the sentence should read "In addition, whereas the neostigmine-induced bradycardia is blocked by selective nicotinic receptor antagonists, the block occurs at doses much greater than those at which these drugs act as selective antagonists. ${ }^{3 "}$ 